\title{
Screening of biodegradation potential for $n$-alkanes and polycyclic aromatic hydrocarbon among isolates from the north-western tip of Pahang
}

\author{
Nur Hafizah Azizan, ${ }^{a, *}$, Mohd Syafiq Abdul Rahimª Zaima Azira Zainal Abidin", \\ Mohd Faez Sharifa, Ahmed Jalal Khan Chowdhury, ${ }^{\mathrm{b}, *}$ \\ ${ }^{a}$ Department of Biotechnology, Kulliyyah of Science, International Islamic University Malaysia, 25200 Kuantan, Pahang, \\ Malaysia, Tel.+6095704000; Ext. 2623; email: fizahazizan@iium.edu.my (N.H. Azizan) \\ ${ }^{b}$ Department of Marine Science, Kulliyyah of Science, International Islamic University Malaysia, 25200 Kuantan, Pahang, \\ Malaysia, Tel.+6095704000; Ext. 2623; email: jkchowdhury@iium.edu.my (A.J.K. Chowdhury)
}

Received 24 June 2019; Accepted 15 December 2019

\section{A B S T R A C T}

\begin{abstract}
This study has successfully screened for a few selected enzyme activities and hydrocarbon-degrading capability of 18 bacterial isolates from the north-western tip of Pahang. The bacterial isolates were known belong to genus Pseudomonas, Stenotrophomonas, Acinetobacter, Serratia, Bacillus and Exiguobacterium. Among them there are more than $80 \%$ were lactase and amylase producers, while only $44 \%$ were protease and lipase producers. Gravimetric analysis was performed to test the capability of degrading $n$-alkanes and polycyclic aromatic hydrocarbons (PAHs). A statistical analysis, Statistical Package for the Social Sciences (SPSS) was used for hydrocarbon utilization analysis The overall degradation of $n$-alkanes was revealed to be not significant. On the other hand, based on the statistical analysis PAHs utilization was significant. Isolate A3i was chosen as the best utilizer of $n$-alkanes, while isolate A2 was chosen for the best PAHs degrader.
\end{abstract}

Keywords: Degrader; Enzymes; Gravimetric analysis; Polycyclic aromatic hydrocarbon; $n$-alkanes

\section{Introduction}

Hydrocarbon pollution by petroleum products has imparted the main causes of environmental pollution occurred on terrestrial and water environment. This was caused by the accidental spillage of petroleum refined products or it can be from the releases of manufacturing waste by various industries.

The existence of various hydrocarbons contaminants around us gives big implication to human and environment. The high toxicity level of some hydrocarbon compounds was already proven before. For instance, the metabolites formed by the transformation of polycyclic aromatic hydrocarbons (PAHs) were known to be mutagenic, carcinogenic and teratogenic [1]. These compounds will bind to

\footnotetext{
* Corresponding authors.
}

and disrupt the DNA and RNA, causing the formation of a tumour. The environmental effects due to hydrocarbon contaminations were also very serious. Many seabirds and other marine organisms were found dead due to the wreckage of oil tankers [2].

The solutions of hydrocarbon contamination could be varied. For the remediation of oil spillage that occurs in the marine environment, there are several chemical and mechanical methods to be used. However, these methods are very costly, besides they are difficult to be applied in certain conditions or places, such as on a beach or other terrestrial areas. Thus, under this situation, the application of bioremediation is highly needed to resolve this problem. Bioremediation has been viewed as an appropriate remediation technique that is inexpensive, environmentally safe and more effective for hydrocarbon contamination cases [3]. 
Bioremediation is a concept that utilized bacteria or other microorganisms to degrade any material into other compounds $[4,5]$. The hydrocarbon can be utilized by microorganisms for several purposes. Microorganisms need those compounds to use as a sole energy source and for growth [6]. Following this, it says that hydrocarbon-utilized microbes can be used to be exploited based on its dependencies on carbon source to convert the hydrocarbon compound into other much simpler molecules.

\section{Materials and methods}

\subsection{Soil samples collection}

Soil samples were collected from a laboratory collection [7].

\subsection{Screening of amylase, lactase, lipase and protease activities}

\subsubsection{Amylase}

A single colony was inoculated on starch agar and incubated at $18^{\circ} \mathrm{C}$ for $24 \mathrm{~h}$ followed by flooding the agar with iodine solution for a few minutes. Formation of a clear zone on the agar indicates positive for amylase activity.

\subsubsection{Lactase}

A single colony was inoculated on MacConkey agar followed by incubation at $18^{\circ} \mathrm{C}$ for $24 \mathrm{~h}$. Red or pink colonies formed on the agar indicates positive for lactase activity.

\subsubsection{Lipase}

A single colony was inoculated on tributyrin agar and incubated at $18^{\circ} \mathrm{C}$ for $24 \mathrm{~h}$. Formation of a clear zone around a bacterial colony indicates positive for lipase activity.

\subsubsection{Protease}

A single colony was inoculated on skim-milk agar followed by incubation at $18^{\circ} \mathrm{C}$ for $24 \mathrm{~h}$. Formation of a clear zone around a bacterial colony indicates positive for protease activity.

\subsection{Hydrocarbon degradation test - Gravimetric analysis}

A fresh bacterial culture was prepared by inoculating single colony into a $5 \mathrm{ml} \mathrm{MSM}+1 \%$ engine oil broth and incubated at $18^{\circ} \mathrm{C}$ with shaking at $150 \mathrm{rpm}$ for $48 \mathrm{~h}$. Before the hydrocarbon degradation test, the $\mathrm{OD}_{600}$ of the bacterial culture was determined to be at the range of 0.10.2 . Hydrocarbon supplemented medium was prepared by adding $1 \mathrm{ml}$ of engine oil into $100 \mathrm{ml} \mathrm{MSM}$ broth in a $250 \mathrm{ml}$ conical flask. Then, $1 \mathrm{ml}$ of the prepared inoculum was added to the flask and incubated for $30 \mathrm{~d}$ at $18^{\circ} \mathrm{C}$ with shaking at $150 \mathrm{rpm}$. A control was prepared by using the same medium but without the addition of the inoculum and was also incubated for $30 \mathrm{~d}$ at $18^{\circ} \mathrm{C}$ with shaking at $150 \mathrm{rpm}$. After the incubation period, the bacterial culture was centrifuged at 5,000 rpm for $1 \mathrm{~min}$. The upper layer was transferred into a beaker containing $15 \mathrm{ml} n$-pentane. The mixture was shaken thoroughly and filtered using a filter paper to remove asphaltene compounds in the form of a black precipitate. Next, the remaining $n$-pentane was removed from the oil using a rotary evaporator that was set at $60^{\circ} \mathrm{C}$ on atmospheric pressure.

\subsection{Retaining of n-alkanes and PAHs}

A mixture of silica gel (230-400 mesh ATSM) with $n$-hexane was prepared and poured into a glass column. The column was covered with parafilm to minimize evaporation and was left for overnight. To extract $n$-alkanes, $30 \mathrm{ml}$ of $n$-hexane was added into the remaining oil sample. The mixture was then added into the column and fractions were collected. Fractions collected were labelled as F1. Next, a mixture of $5 \mathrm{ml} n$-hexane and $15 \mathrm{ml}$ dichloromethane was added to the column to bring out PAHs from the oil sample and fractions were collected. Fractions collected were labelled as F2. All fractions (F1 \& F2) were evaporated to dryness at a temperature of $60^{\circ} \mathrm{C}$ and 335 psi. Then, $1 \mathrm{ml}$ of dichloromethane was added to the dried fractions followed by sonication for 1-2 min. Next, F1 and F2 were dried using nitrogen gas and their weight was determined.

\subsection{Analysis of data}

Data analysis was performed using Statistical Package for the Social Sciences (SPSS) (Version 16.0). Based on the data obtained, the variables were identified.

\section{Results and discussions}

\subsection{Screening for enzyme activities}

The screening of enzyme activities was done for lactase, protease, amylase and lipase to identify how the bacterial isolates act on several substrates. The isolates were grown on specific plates for each test. The examples of positive and negative reactions for each test were presented in Fig. 1.

Table 1 showed the enzyme activities for each isolate. Positive results indicated by the detection of enzymes activities, while negative results were recorded when no enzyme activity was detected. From the table, it showed that all samples were producing at least one enzyme. Two out of 18 isolates were found producing all four types of tested enzymes (C3 and D2). This means that each of this isolate has the potential to be utilized at an industrial level for any related applications in the future. At a commercial level, lactase, amylase, protease and lipase have been widely used in dairy products, bread making, detergent formulation, paper production, textile manufacturing and other industries including medicinal and pharmaceutical products [8-10].

\subsection{Hydrocarbon degradation test (gravimetric analysis)}

For gravimetric analysis, the independent variable was the isolates, while the dependent variable was the weight of the remaining compound. The hypotheses were:

Null hypothesis $\left(H_{0}\right)$ : There was a significant difference in the gradation of hydrocarbon compounds in this study.

Alternative hypothesis $\left(H_{a}\right)$ : There was no significant difference in the degradation of hydrocarbon compounds in this study. 

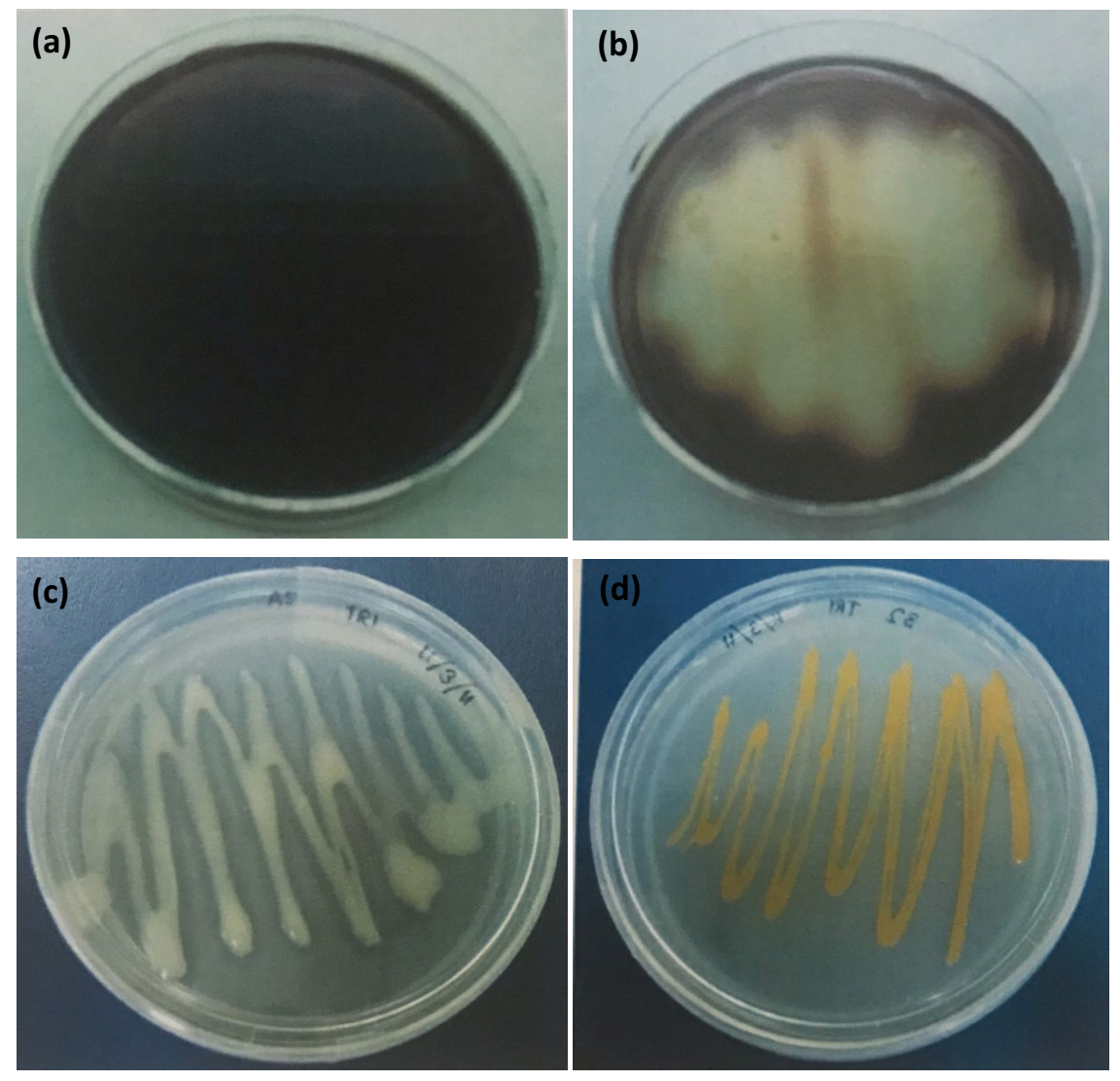

Fig. 1. (a) No formation of clear zone for amylase test, (b) formation of clear zone observed for amylase test, (c) clear zone formation for lipase activity, and (d) no formation of clear zone for lipase activity.

Table 1

Enzyme activity test

\begin{tabular}{|c|c|c|c|c|c|}
\hline $\begin{array}{l}\text { Isolates } \\
\text { (designation) }\end{array}$ & Isolates (possible species comparing to NCBI database) & Lactase & Amylase & Protease & Lipase \\
\hline A1 & Pseudomonas sp. S27 & + & + & - & - \\
\hline A2 & Bacillus cereus strain Aj0803191A & + & + & + & - \\
\hline A3i & Stenotrophomonas sp. 412 (2010) & + & + & - & + \\
\hline A3ii & Stenotrophomonas maltophilia & + & + & - & - \\
\hline A4 & Pseudomonas putida strain BJ10 & + & + & - & - \\
\hline B1 & Pseudomonas sp. G60 & + & + & - & - \\
\hline B2 & Exiguobacterium sp. D25 (2010) & - & + & + & - \\
\hline B4 & Acinetobacter baumannii strain Ab8 & + & + & - & + \\
\hline $\mathrm{C} 1$ & Pseudomonas sp. CMR12a & - & + & + & + \\
\hline $\mathrm{C} 2$ & Serratia sp. endosymbiont of Nilaparvata lugens clone M149 & + & + & + & - \\
\hline C3 & Stenotrophomonas sp. Pm3 & + & + & + & + \\
\hline D1 & Pseudomonas aeruginosa clone AZ130 & + & + & + & - \\
\hline D2 & Pseudomonas aeruginosa strain E70 & + & + & + & + \\
\hline D3 & Acinetobacter sp. WJ07 & + & + & - & + \\
\hline E1 & Pseudomonas taiwanensis strain CAIM 837 & + & + & - & - \\
\hline E2 & $\begin{array}{l}\text { Gamma proteobacterium ectosymbiont of Symmetromphalus aff. } \\
\text { hageni clone C5 }\end{array}$ & + & + & - & + \\
\hline E3 & Acinetobacter johnsonii strain GRA732 & + & - & + & - \\
\hline E4 & Serratia marcescens strain JNB5-1 & - & - & - & + \\
\hline
\end{tabular}

NCBI: The National Centre for Biotechnology Information 
Kruskal-Wallis test was used to analyse the data for Fraction 1, while one-way analysis of variance (ANOVA) was used for fraction 2 . For both tests, $p \leq 0.05$ was used. The outcome of the analysis was simplified as in Tables 2 and 3.

Tables 2 and 3 showed the statistical analysis for both hydrocarbon compounds (Fraction 1 for $n$-alkanes while Fraction 2 for PAHs). From the tables, the significant value for Fraction 1 was 0.448 . This value was larger than 0.05 . Thus, the test was not significant. The null hypothesis was rejected and the alternative hypothesis was accepted. This indicates that the degradation of $n$-alkanes was not significant. For Fraction 2, the significant value was 0.014 . This value was lower than 0.05 . So, the test was significant. The hypothesis was not rejected. Therefore the degradation of PAHs was significant.

Among all tested bacteria, the best degrader for $n$-alkanes was A3i. This strain showed the highest percentage (53.85\%) of $n$-alkane compounds degradation. This was followed by A2, with $23.08 \%$ and C3 with $11.54 \%$ of degradation. The rest have low $n$-alkane utilization performance. Also, A2 was the best PAHs degrader with the degradation percentage of $61.05 \%$. The second and third best PAHs degraders were $\mathrm{C} 1$ and E1 with the percentage of degradation of $57.54 \%$ and $31.66 \%$, respectively.

In this study, isolates A3i (Stenotrophomonas sp. 412 (2010)) and A2 (Bacillus cereus strain Aj080319IA) were recorded as the best hydrocarbon degraders. Isolate $\mathrm{A} 3 \mathrm{i}$ degraded $53.85 \%$ of $n$-alkanes while isolate A2 degraded about $61.05 \%$ of PAHs. However, both of these strains belong to genera that are not common in hydrocarbon degradation studies. The strains under these genera were rarely isolated from oil-contaminated soil in a cold region. According to [11], laboratory studies had confirmed the genera that were commonly related to hydrocarbon degradation activities are Rhodococcus and Acinetobacter for n-alkanes, and Sphingomonas for PAHs, while Pseudomonas degrading both compounds. However, there were still some researches that found positive results for genera Stenotrophomonas and Bacillus on hydrocarbon degradation [12-14].

There were some current researches around the world that support the findings of $n$-alkanes degradation by Stenotrophomonas sp. A research found that a strain of Strenotrophomonas maltophilia with an optimum growth temperature of $15^{\circ} \mathrm{C}$ can degrade oil up to $80.16 \%$ where $\mathrm{C}^{13}$ to $\mathrm{C}^{32} n$-alkanes were completely degraded [12]. Ganesh and Lin also recorded almost the same result, with $83.12 \%$ of hydrocarbon were successfully degraded [13].

Previous studies on Bacillus sp. also recorded positive results. Several types of low molecular weight of PAHs (naphthalene, 1-methylnaphthalene, 2-ethyl naphthalene, phenanthrene) were significantly degraded [15-20]. In the same study, the mineralization of several tested high molecular weight PAH also showed a positive result. Phenanthrene, pyrene and benzo[a]pyrene were found significantly mineralized. This result was consistent with another study where the degradation activity on PAHs and

Table 2

Statistical analysis of hydrocarbon compound degradation for fraction 1 ( $n$-alkanes)

\begin{tabular}{|c|c|c|c|c|c|}
\hline $\begin{array}{l}\text { Isolates } \\
\text { (designation) }\end{array}$ & $\begin{array}{l}\text { Isolates (possible species comparing to } \\
\text { NCBI database) }\end{array}$ & $N$ & Weight $(\mathrm{g})$, mean & Chi-Square $^{a}(\mathrm{df})$ & $p$-value \\
\hline Control & Pseudomonas sp. S27 & 2 & $0.0026 \pm 0.0004$ & $18.113(18)$ & 0.448 \\
\hline A1 & Bacillus cereus strain Aj0803191A & 2 & $0.0029 \pm 0.0002$ & & \\
\hline $\mathrm{A} 2$ & Stenotrophomonas sp. 412 (2010) & 2 & $0.0020 \pm 0.0011$ & & \\
\hline $\mathrm{A} 3 \mathrm{i}$ & Stenotrophomonas maltophilia & 2 & $0.0012 \pm 0.0002$ & & \\
\hline A3ii & Pseudomonas putida strain BJ10 & 2 & $0.0060 \pm 0.0022$ & & \\
\hline A4 & Pseudomonas sp. G60 & 2 & $0.0045 \pm 0.0016$ & & \\
\hline B1 & Exiguobacterium sp. D25 (2010) & 2 & $0.0476 \pm 0.0651$ & & \\
\hline B2 & Acinetobacter baumannii strain Ab8 & 2 & $0.0090 \pm 0.0086$ & & \\
\hline B4 & Pseudomonas sp. CMR12a & 2 & $0.0051 \pm 0.0047$ & & \\
\hline $\mathrm{C} 1$ & $\begin{array}{l}\text { Serratia sp. endosymbiont of Nilaparvata } \\
\text { lugens clone M149 }\end{array}$ & 2 & $0.0605 \pm 0.0781$ & & \\
\hline $\mathrm{C} 2$ & Stenotrophomonas sp. Pm3 & 2 & $0.0256 \pm 0.0291$ & & \\
\hline $\mathrm{C} 3$ & Pseudomonas aeruginosa clone AZ130 & 2 & $0.0023 \pm 0.0051$ & & \\
\hline D1 & Pseudomonas aeruginosa starin E70 & 2 & $0.0092 \pm 0.0122$ & & \\
\hline D2 & Acinetobacter sp. WJ07 & 2 & $0.0064 \pm 0.0083$ & & \\
\hline D3 & Pseudomonas taiwanensis strain CAIM 837 & 2 & $0.0115 \pm 0.0105$ & & \\
\hline E1 & $\begin{array}{l}\text { Gamma proteobacterium ectosymbiont of } \\
\text { Symmetromphalus aff. hageni clone C5 }\end{array}$ & 2 & $0.0053 \pm 0.0046$ & & \\
\hline E2 & Acinetobacter johnsonii strain GRA732 & 2 & $0.0119 \pm 0.0011$ & & \\
\hline E3 & Serratia marcescens strain JNB5-1 & 2 & $0.0378 \pm 0.0378$ & & \\
\hline E4 & Pseudomonas sp. S27 & 2 & $0.0133 \pm 0.0252$ & & \\
\hline
\end{tabular}

${ }^{a}$ Kruskal-Wallis test

${ }^{*} p \leq 0.05$ 
Table 3

Statistical analysis of hydrocarbon compound degradation for fraction 2 (PAHs)

\begin{tabular}{|c|c|c|c|c|c|}
\hline Isolates & $\begin{array}{l}\text { Isolates (possible species comparing } \\
\text { to NCBI database) }\end{array}$ & $N$ & Weight $(\mathrm{g})$, mean & Chi-Square $^{a}(\mathrm{df})$ & $p$-value \\
\hline Control & Pseudomonas sp. S27 & 2 & $0.0398 \pm 0.0059$ & $2.875(18)$ & 0.014 \\
\hline A1 & Bacillus cereus strain Aj0803191A & 2 & $0.0397 \pm 0.0325$ & & \\
\hline A2 & Stenotrophomonas sp. 412 (2010) & 2 & $0.0155 \pm 0.0008$ & & \\
\hline A3i & Stenotrophomonas maltophilia & 2 & $0.1067 \pm 0.0158$ & & \\
\hline A3ii & Psedomonas putida strain BJ10 & 2 & $0.0638 \pm 0.0566$ & & \\
\hline$A 4$ & Pseudomonas sp. G60 & 2 & $0.0450 \pm 0.0041$ & & \\
\hline B1 & Exiguobacterium sp. D25 (2010) & 2 & $0.0578 \pm 0.0402$ & & \\
\hline B2 & Acinetobacter baumannii strain Ab8 & 2 & $0.1159 \pm 0.0179$ & & \\
\hline B4 & Pseudomonas sp. CMR12a & 2 & $0.0351 \pm 0.0100$ & & \\
\hline $\mathrm{C} 1$ & $\begin{array}{l}\text { Serratia sp. endosymbiont of Nilaparvata lugens } \\
\text { clone M149 }\end{array}$ & 2 & $0.0169 \pm 0.0094$ & & \\
\hline $\mathrm{C} 2$ & Stenotrophomonas sp. Pm3 & 2 & $0.0648 \pm 0.0455$ & & \\
\hline C3 & Pseudomonas aeruginosa clone AZ130 & 2 & $0.0776 \pm 0.0077$ & & \\
\hline D1 & Pseudomonas aeruginosa starin E70 & 2 & $0.0927 \pm 0.0199$ & & \\
\hline D2 & Acinetobacter sp. WJ07 & 2 & $0.0854 \pm 0.0371$ & & \\
\hline D3 & Pseudomonas taiwanensis strain CAIM 837 & 2 & $0.1061 \pm 0.0136$ & & \\
\hline E1 & $\begin{array}{l}\text { Gamma proteobacterium ectosymbiont of } \\
\text { Symmetromphalus aff. hageni clone C5 }\end{array}$ & 2 & $0.0272 \pm 0.0036$ & & \\
\hline E2 & Acinetobacter johnsonii strain GRA732 & 2 & $0.0311 \pm 0.0383$ & & \\
\hline E3 & Serratia marcescens strain JNB5-1 & 2 & $0.0463 \pm 0.0592$ & & \\
\hline E4 & Pseudomonas sp. S27 & 2 & $0.1258 \pm 0.0017$ & & \\
\hline
\end{tabular}

aOne way ANOVA

${ }^{*} p \leq 0.05$

other hydrocarbons by Bacillus cereus can be detected after $3 \mathrm{~d}$ of incubation [14].

\section{Conclusions}

The screening of lactase, amylase, protease and lipase activities suggested that each of these isolates have their commercial value to be exploited at the industrial level. The overall result of this test was very favourable, with each isolate showed its potential on different substrates. The ability to breakdown lactose, starch and lipid molecules gives this bacterial strain a high commercial value.

The degradation of $n$-alkanes in this study was not significant. On the other hand, the degradation of PAHs in this study was found to be significant with a $p$-value of less than 0.05 . The degradation of PAHs compounds had a significant increase after $30 \mathrm{~d}$ incubation at $18^{\circ} \mathrm{C}$. In this study, $\mathrm{A} 3 \mathrm{i}$ (Stenotrophomonas sp. 412 (2010)) and A2 (Bacillus cereus strain Aj080319IA) were recorded as the best hydrocarbon degraders.

\section{References}

[1] S. Harrad, The Environmental Behavior of Persistent Organic Pollutants, R.M. Harrison, Ed., Pollution: Causes, Effects and Control, United Kingdom: Royal Society of Chemistry, Boston/Dordrecht/London: Kluwer Academic Publishers, 2001, pp. $445-473$.

[2] C.H. Walker, Organic Pollutants: An Ecotoxicological Perspective (2nd ed.), Boca Raton, CRC Press, 2009.
[3] R. Margesin, F. Schinner, Biodegradation and bioremediation of hydrocarbons in extreme environments, Appl. Microbiol. Biotechnol., 56 (2001) 650-663.

[4] M.D., Aitken, T.C. Long, Biotransformation, Biodegradation and Bioremediation of Polycyclic Aromatic Hydrocarbons, A. Singh, O.P. Ward, Eds., Biodegradation and Bioremediation, Springer, Berlin/Heidelberg, 2004, pp. 83-124.

[5] J.D. Coates, Anaerobic Biodegradation of Hydrocarbon, A. Singh, O.P. Ward, Eds., Biodegradation and Bioremediation, Springer, Verlag Berlin Heidelberg, 2004, pp. 57-82.

[6] K. Phlol, H. Leskovsek, Biodegradation of motor oil in water, Acta Chim. Slov., 49 (2001) 279-289.

[7] N.H. Azizan, S.Z. Rami, R.R. Saedudin, S. Kasim, Phylogenetic study of presumptive oil-degrading microbes isolated from the North-Western tip of Pahang, Int. J. Integr. Eng., 10 (2018) 128-132.

[8] W. Aehle, Enzymes in Industry, Production and Applications, 2nd ed., WILEY-VCH Verlag GmbH \& Co. KGaA, Weinheim, 2004.

[9] S. Kanhaiya, S. Singh, C.K. Singh, V.K. Srivastava, A. Patra, Geomorphic evolution of the Dongar River Basin, Son Valley, Central India, Geol. Ecol. Landscapes, 3 (2019) 269-281.

[10] Z. Maryam, A.H. Hazrin, A. Hizrri, A. Norhidayah, N. Samsuddin, M.A. Mohd Shukri, Association of particulate matter (Pm) with respiratory symptoms among children in selected primary schools in Pahang, J. Clean WAS, 2 (2018) 11-15.

[11] M.O. Eyankware, O.O. Omo-Irabor, An integrated approach to groundwater quality assessment in determining factors that influence the geochemistry and origin of sandstone aquifers Southern Niger delta region of Nigeria, Malaysian J. Geosci., 3 (2019) 23-32.

[12] M.T. Sarwar, H.H. Zhan, J.X. Yang, W.J. Shi, Y. Tao, B.J. Liu, S.S. Tang, Mitigation techniques to overcome water scarcity issues, Water Conserv. Manage., 3 (2019) 30-31. 
[13] Z.N. Fogwe, S.J.P. Tume, M. Fouda, Eucalyptus tree colonization of the Bafut-Ngemba forest reserve, North West region, Cameroon, Environ. Ecosyst. Sci., 3 (2019) 12-16.

[14] A. Pandey, C. Webb, C.R. Soccol, C. Larroche, Enzyme Technology, Springer, New Delhi, 2006, pp. 297-318.

[15] T. Satyanarayana, J.L.U.M. Rao, M. Ezhilvannan, a-Amylases, A. Pandey, C. Webb, C.R. Soccol, C. Larroche, Eds., Enzyme Technology, New Delhi, Springer, 2006, pp. 189-220.

[16] J. Aislabie, D.J. Saul, J.M. Foght, Bioremediation of hydrocarboncontaminated polar soils, Extremophiles, 10 (2006) 171-179.

[17] L. Bing, Z. Qing-fang. Screening and degrading characteristics of LHB16, Biotechnology, 5 (2010) 83-85.
[18] A. Ganesh, J. Lin, Diesel degradation and biosurfactant production by gram-positive isolates, Afr. J. Biotechnol., 8 (2009) 5847-5854.

[19] A.P. Mariano, D.M. Bonotto, D.F. Angelis, M.P.S. Pirollo, J. Contiero, Biodegradability of commercial and weathered diesel oils, Braz. J. Microbiol., 39 (2008) 133-142.

[20] M.D. Aitken, W.T. Stringfellow, R.D. Nagel, C. Kazunga, S. Chen, Characteristics of phenanthrene-degrading bacteria isolated from soils contaminated with polycyclic aromatic hydrocarbon, J. Microbiol., 44 (1998) 743-752. 